\title{
Comment on "Aerosol radiative forcing and climate sensitivity deduced from the Last Glacial Maximum to Holocene transition", by P. Chylek and U. Lohmann, Geophys. Res. Lett., 2008
}

\author{
J. C. Hargreaves and J. D. Annan \\ Global Change Projection Research Program, Research Institute for Global Change, JAMSTEC, 3173-25 Showa-machi, \\ Kanazawa-ku, Yokohama City, Kanagawa, 236-0001, Japan
}

Received: 16 October 2008 - Published in Clim. Past Discuss.: 22 December 2008

Revised: 27 February 2009 - Accepted: 30 March 2009 - Published: 8 April 2009

\begin{abstract}
In a recent paper, Chylek and Lohmann (2008) used data from the Vostok ice core together with simple energy balance arguments to simultaneously estimate both the dust radiative forcing effect and the climate sensitivity, generating surprisingly high and low values for these respective parameters. However, their results depend critically on their selection of single unrepresentative data points from time series which exhibit a large amount of short-term variability, and are highly unstable with respect to other arbitrarily selected data points. When temporal averages are used in accordance with accepted norms within the paleoclimate community, the results obtained are entirely unremarkable and in line with previous analyses.
\end{abstract}

\section{Introduction}

The sensitivity of the climate system to external forcing has long been a subject of much research, the bulk of which has concluded that the climate sensitivity to a doubling of $\mathrm{CO}_{2}$ is likely to lie in the range $2-4.5^{\circ} \mathrm{C}$ (IPCC 2007 : Summary for Policymakers, Solomon et al., 2007; Knutti and Hegerl, 2008). Chylek and Lohmann (2008) (hereafter CL08) claim to have found evidence that the true value is much lower, around $1.8^{\circ} \mathrm{C}$, and present two main arguments in support of their claim. The bulk of their paper focusses on an energybalance analysis of data from the Vostok ice core (Petit et al., 1999). In this short comment we discuss the validity of their approach in Sect. 2, and illustrate that their results are highly sensitive to the specific data points that they selected. CL08 also present results from a GCM simulation in which high

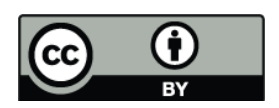

Correspondence to: J. C. Hargreaves (jules@jamstec.go.jp) dust loading is imposed, to estimate the net radiative forcing effect. However, this simulation has a serious flaw which strongly biases and invalidates their result, as we explain in Sect. 3 .

\section{Analysis of ice core data}

CL08 analyse the Vostok ice core using simple energy balance arguments, assuming radiative equilibrium and estimating the climate sensitivity as the ratio of global temperature change to total radiative forcing over a given interval. The radiative forcing effect of changes in atmospheric dust loading over the paleoclimate record is a significant uncertainty in this calculation, so CL08 use two different intervals - specifically, the differences between the Last Glacial Maximum (LGM) and Holocene, and those between the LGM and $42 \mathrm{ka}$ before present - to simultaneously estimate both the climate sensitivity and the dust forcing effect, via the following equation:

$$
\frac{\Delta T_{1}}{F_{\mathrm{GHG} 1}+F_{\mathrm{ALB} 1}+58 X}=\frac{\Delta T_{2}}{F_{\mathrm{GHG} 2}+F_{\mathrm{ALB} 2}+53 X}
$$

where $\Delta T$ denotes the temperature change over the first or second interval (indexed by the subscript), $F_{\mathrm{GHG}}$ and $F_{\mathrm{ALB}}$ are radiative forcings due to changes in greenhouse gases and planetary albedo, respectively, and $X$ is the (unknown) forcing per unit change in dust. After solving for $X$, the climate sensitivity is given by the expression on either side of this equation.

CL08 used data obtained from the Vostok ice core (Petit et al., 1999), which we re-plot in Fig. 1. Their analysis was based on the extremal data points for temperature and dust (P. Chylek, personal communication, 2008), which we have highlighted in red. That is, from the temperature data, they

Published by Copernicus Publications on behalf of the European Geosciences Union. 


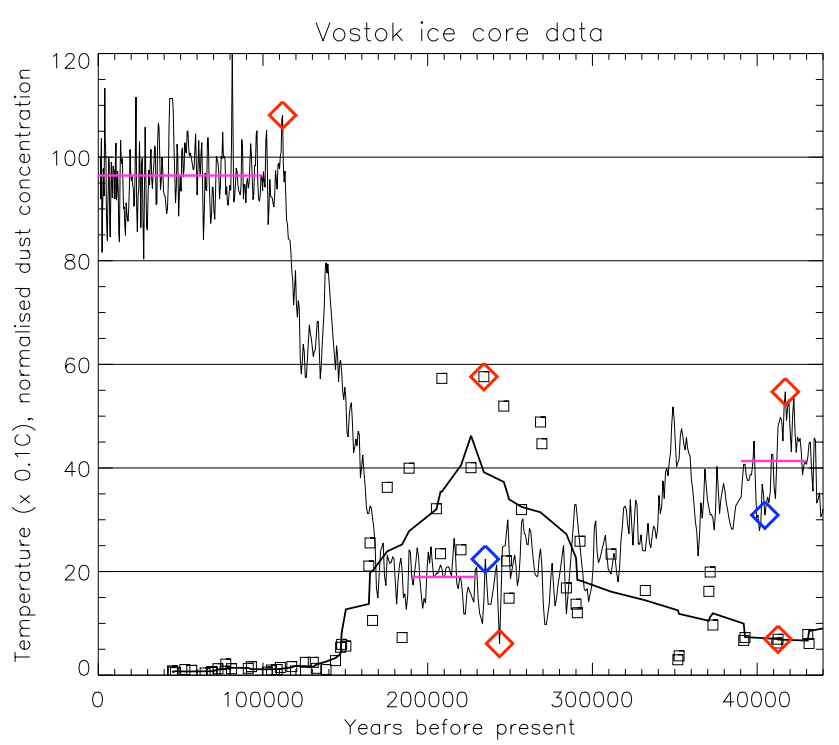

Fig. 1. Temperature (thin black line) and dust data (squares) from Vostok ice core. Thick black line is a 5-point smooth of the dust data. Red diamonds indicate the points selected by CL08. Blue diamonds indicate alternative temperature data points, and magenta lines indicate averages over the indicated periods.

picked the lowest value around the LGM period, the highest temperature around $42 \mathrm{ka}$ and also a warm peak at the start of the Holocene, without providing any explicit justification of these choices. They also selected the highest data point for dust within the LGM period, despite it not being the closest data point in time to the temperature point that they used. It is apparent by eye that the dust and temperature time series have strong variability, and we now show that their results are highly sensitive to the specific data points that they chose, by presenting a methodologically identical analysis based on different data points.

To demonstrate this, we selected a local temperature maximum during the LGM interval, which is actually closer in time to the dust value than the temperature minimum that CL08 used. We also choose a local minimum in the temperature data close to $41 \mathrm{ka} \mathrm{BP}$. These points are indicated in blue in Fig. 1. We then followed the same procedure as CL08, estimating the global temperature change as $40-50 \%$ of the local temperature change, with other estimates from their analysis left unaltered. Values for dust, greenhouse gases, and albedo (including uncertainties for the latter) were not altered from CL08's choices. When exactly the same analysis procedure is followed with these slightly modified input data, the results are strikingly different. The dust forcing factor, $X$, is now found to be negative, with a dust forcing for the LGM to Holocene transition of approximately $-1 \pm 0.4 \mathrm{Wm}^{-2}$ (at one standard deviation), incompatible with CL08's estimate of $3.3 \pm 0.8 \mathrm{Wm}^{-2}$. The climate sensitivity to a doubling of $\mathrm{CO}_{2}$ is now estimated to be about $3.5^{\circ} \mathrm{C}$, with a $95 \%$ range of $2.6-4.5^{\circ} \mathrm{C}$, compared to CL08's estimate of $1.3-2.3^{\circ} \mathrm{C}$.
The explanation for this discrepancy is very straightforward. The simple global energy balance equation presented by CL08 simply cannot be expected to capture the high frequency variability that is observed in these local records. As Mix et al. (2001) observe, "regional temperature records do not necessarily reach minimum values at the same time, so a definition (of the LGM) based on the coldest observed temperature or some other local extreme conditions would be inappropriate." Therefore, rather than picking individual points, the normal approach has been to use temporal averages over some reasonable time scale. The LGM climate state has been defined in the literature to be well characterised by the interval 19-23 ka BP (Mix et al., 2001; Kucera et al., 2005), so we average the temperatures over this period. It is less clear that the climate system is close to equilibrium around the $41 \mathrm{ka}$ era, but for consistency we follow the same procedure, averaging temperatures over an interval of the same length centred on $41 \mathrm{kaBP}$, also shown in the figure. For dust forcing, we also average the data over the same intervals, which gives a value of 38 units for the LGM to Holocene transition, and 32 units for LGM to $41 \mathrm{ka}$.

When these values are used in the energy balance equation, they provide an estimated dust forcing of $0.9 \pm 1.2 \mathrm{Wm}^{-2}$ for the LGM to Holocene transition, and an estimated climate sensitivity of $1.7-3.4^{\circ} \mathrm{C}$, with a median of $2.4^{\circ} \mathrm{C}$. The estimated dust forcing agrees well with that derived from realistic GCM simulations (see Sect. 3) and the resulting climate sensitivity is in line with most energy-balance analyses of paleoclimatic data (e.g. Hansen et al., 1993).

While the upper bound of this result is still a little on the low side compared to some estimates, we have omitted some major sources of uncertainty. Perhaps most notably, this type of analysis implicitly assumes that the sensitivity is constant for a wide range of different forcings (which are themselves assumed to combine linearly) and also for radically different background climatic conditions. Accounting for these factors would certainly increase the uncertainty of this result, and there is some evidence that the feedbacks in a colder climate state may be slightly lower than for a warmer one (Hargreaves et al., 2007; Yoshimori et al., 2009). However results may vary between models, and there is still much debate over how useful paleoclimate analyses can be for informing on future climate changes (Schneider von Deimling et al., 2006; Crucifix, 2006). The validity of the Vostok data around $42 \mathrm{ka}$ as representative of global climate changes is also disputed (Ganopolski and von Deimling, 2008), although our 4000 -year smoothing may help to reduce this problem. Nevertheless, we can at least draw the conclusion that these paleoclimate data do not pose any significant challenge to the widely-held view that climate sensitivity is likely to lie in the range $2-4.5^{\circ} \mathrm{C}$ (IPCC 2007: Summary for Policymakers, Solomon et al., 2007) and may indeed provide some support for a figure in this range. 
Examining the data underlying CL08's analyses of the previous glacial terminations (their Table 1) reveals that again they have picked unrepresentative extrema in both the dust and temperature time series. Moreover, the largest drops in the dust values lead the significant temperature changes by a substantial margin (exceeding 10000 years in two cases), which by itself would appear to refute either the implicit hypothesis of CL08 that the planet is in radiative equilibrium over much shorter time scales, or their result that the dust forcing makes a large contribution to the energy balance.

\section{Model simulation}

CL08 also perform a simulation using a GCM, in which they use present day boundary conditions but greatly increase the supply of natural dust and aerosol by scaling up current sources by factors of 4 and 2, respectively, resulting in a net global forcing of around $-3 \mathrm{Wm}^{-2}$. However, more complete model simulations have previously been performed in which realistic LGM boundary conditions and dust sources are used, which show a net global change in forcing due to dust of around $-1 \mathrm{Wm}^{-2}$ (Claquin et al., 2003). One likely problem with the CL08 simulation is the absence of large ice sheets. This can be expected to have biased their results, as an increase in dust actually results in a positive forcing over realistic LGM ice sheets (Overpeck et al., 1996; Claquin et al., 2003). Thus, although CL08's model estimate for dust forcing seems broadly reasonable in the tropical region, it is substantially too high for latitudes poleward of $45^{\circ}$ (Claquin et al., 2003) and therefore also globally.

\section{Conclusions}

The analysis of CLO8 is based on the selection of local extrema in time series which show high temporal variability, and moreover the data points they used are not even temporally coincident. Thus, these data points cannot adequately represent the long-term energy balance of the climate system, and we have shown that their results are highly unstable with respect to the particular data points selected. When the noise of short-term natural variability is reduced by temporal averaging, the results come into line with previous analyses of these and similar data (e.g. Hansen et al., 1993). Thus the authors have not presented any significant evidence to challenge existing estimates of climate sensitivity (Solomon et al., 2007).

Edited by: T. Kiefer

\section{References}

Chylek, P. and Lohmann, U.: Aerosol radiative forcing and climate sensitivity deduced from the Last Glacial Maximum to Holocene transition, Geophys. Res. Lett., 35, L04804, 1-5, 2008.

Claquin, T., Roelandt, C., Kohfeld, K. E., Harrison, S. P., Tegen, I., Prentice, I. C., Balkanski, Y., Bergametti, G., Hansson, M., Mahowald, N., Rodhe, H., and Schulz, M.: Radiative forcing of climate by ice-age atmospheric dust, Clim. Dynam., 20, 193202, 2003.

Crucifix, M.: Does the Last Glacial Maximum constrain climate sensitivity, Geophys. Res. Lett., 33, L18701, doi:10.1029/2006GL027137, 2006.

Ganopolski, A. and von Deimling, T.: Comment on "Aerosol radiative forcing and climate sensitivity deduced from the Last Glacial Maximum to Holocene transition" by Petr Chylek and Ulrike Lohmann, Geophys. Res. Lett., 35, L23703, doi:10.1029/2008GL033888, 2008.

Hansen, J., Lacis, A., Ruedy, R., Sato, M., and Wilson, H.: How sensitive is the world's climate?, Natl. Geog. Soc. Res. Exploration, 9, 142-158, 1993.

Hargreaves, J. C., Abe-Ouchi, A., and Annan, J. D.: Linking glacial and future climates through an ensemble of GCM simulations, Clim. Past, 3, 77-87, 2007, http://www.clim-past.net/3/77/2007/.

Knutti, R. and Hegerl, G.: The equilibrium sensitivity of the Earth's temperature to radiation changes, Nature Geoscience, 1, 735743, 2008.

Kucera, M., Rosell-Melé, A., Schneider, R., Waelbroeck, C., and Weinelt, M.: Multiproxy approach for the reconstruction of the glacial ocean surface (MARGO), Quaternary Sci. Rev., 24, 813819, 2005.

Mix, A., Bard, E., and Schneider, R.: Environmental processes of the ice age: land, oceans, glaciers (EPILOG), Quaternary Sci. Rev., 20, 627-657, 2001.

Overpeck, J., Rind, D., Lacis, A., and Healy, R.: Possible role of dust-induced regional warming in abrupt climate change during the last glacial period, Nature, 384, 447-449, 1996.

Petit, J., Jouzel, J., Raynaud, D., Barkov, N., Barnola, J., Basile, I., Bender, M., Chappellaz, J., Davis, M., Delaygue, G., et al.: Climate and atmospheric history of the past 420000 years from the Vostok ice core, Antarctica, Nature, 399, 429-436, 1999.

Schneider von Deimling, T., Held, H., Ganopolski, A., and Rahmstorf, S.: Climate sensitivity estimated from ensemble simulations of glacial climate, Clim. Dynam., 27, 149-163, 2006.

Solomon, S., Qin, D., Manning, M., Chen, Z., et al.: Climate change 2007: The physical science basis, Contribution of the Working Group I to the Fourth Assessment Report of the Intergovernmental Panel on Climate Change, 2007.

Yoshimori, M., Yokohata, T., and Abe-Ouchi, A.: A Comparison of Climate Feedback Strength between $\mathrm{CO}_{2}$ Doubling and LGM Experiments, J. Climate, doi:10.1175/2009JCLI2801.1, in press, 2009. 